IRA-International Journal of Management \& Social Sciences

ISSN 2455-2267; Vol.07, Issue 02 (2017)

Pg. no. 342-354

Institute of Research Advances

http://research-advances.org/index.php/RAJMSS

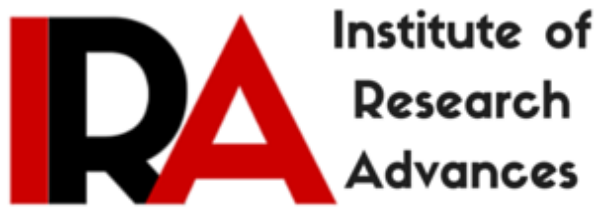

\title{
Demonetization: A Ripple Effect on Indian Economy
}

\section{Dr. Farhat Mohsin}

Assistant Professor, Manav Rachna International University Faridabad, India.

\section{Stuti Sahni}

Research Scholar, IGNOU Delhi, India.

Type of Review: Peer Reviewed.

DOI: http://dx.doi.org/10.21013/jmss.v7.n2.p26

\section{How to cite this paper:}

Mohsin, F., \& Sahni, S. (2017). Demonetization: A Ripple Effect on Indian Economy. IRAInternational Journal of Management \& Social Sciences (ISSN 2455-2267), 7(2), 342-354. doi:http://dx.doi.org/10.21013/jmss.v7.n2.p26

(C) Institute of Research Advances

\section{(cc) EY-NC}

This work is licensed under a Creative Commons Attribution-Non Commercial 4.0 International License subject to proper citation to the publication source of the work.

Disclaimer: The scholarly papers as reviewed and published by the Institute of Research Advances (IRA) are the views and opinions of their respective authors and are not the views or opinions of the IRA. The IRA disclaims of any harm or loss caused due to the published content to any party. 


\section{ABSTRACT}

The value of a nation's currency is the main indicator of its economic growth and development. It is among the major drivers behind the strong foundation of a nation's place on international front. Economics and currency forecasting are both very much inexact sciences. The value of a currency has always been an important source of indicating the economic growth and ensuring the nation's economic health. Currency changes affect our daily routine: whether we are trading in the foreign exchange market, planning our next vacation tour, shopping online goods from other countries etc. The value of domestic currency plays an important role in setting monetary and fiscal policies of a nation and strongly affects the stock and daily commodity market.

The purpose of this research paper is to make the readers aware of current scenario and status of economy due to demonetization in India. This research paper will try to identify factors and issues involved in making India a cashless economy. This study also considers the impact of demonetization on road - side restaurants (RSR) in India with special reference to Delhi-NCR and focuses on the impact of futuristic digital trends in urban cities.

The present study was taken up with an objective to measure the impact of demonetization on road side restaurants. It also revealed the impact of Government's demonetization effort on the cash intensive areas of the economy including everyday shopping for food and supplies The main objective of this study was to evaluate the impact of banning two most useable currencies as legal tender and people's perception on the antecedents of being digital and to assess their selection criteria. The study was an attempt to examine different components involved in vendor's selection decisions and their role in purchase decisions. This paper is based on primary data collected through a self constructed questionnaire. The samples were drawn from the population of 150 respondents. The study was carried out at local markets located at Faridabad and South Delhi and the information collected was depicted by the graphs and tables.

Key Words: Demonetization, Cashless Economy, Globalization, Digitalization, RSR (Road side restaurants)

\section{INTRODUCTION}

Indian fast food industry is changing rapidly. In last two decades, it has been growing significantly. Cooking and eating at home together used to be appreciable issues of Indian culture but because of nuclear family, change in life style and increase in per capita income have made the fast food segment more in fashion. The Indian economy has been witnessed as a developing economy since past many years. In this era of globalization, Indian economy is dependent on many other developed economies. Indian money and banking structure had experienced many major policy changes after 1990. The economic reform which is known as Liberalization Privatization and Globalization L-P-G has given Indian economy a boost on the international front. Many developed and underdeveloped nations have experienced few major economic downturns in the last 50 years. The current financial crisis provides a great opportunity to teach us new ways of fighting with problem.

Demonetization is basically an act of stripping a currency unit of its status as legal tender. It becomes necessary whenever the national currency changes. In this process the national currency is replaced with the new currency unit. The concept of demonetization is not new to the world, when the Euro was introduced; the old national currencies were stripped out, but for the smooth transition of the old currencies remained convertible into Euro for short period of time. On 8 November, 2016 Indian Prime Minister Shri Narender Modi declared that existing INR 500 and 1000 bank notes would no longer be 
accepted as legal tender to put a checkup on the parallel economy. The term demonetization is not new to the Indian economy, the highest demonetization, done by the RBI was the Rs. 10000 note According to RBI data these notes were devalued again in 1946 and again in Jan 1978.

Demonetization is impacting not only the service food industry but all small and big businesses are suffering from it. Roadside restaurants (RSR) are those food joints that offer fast, quickly ready food stuffs at affordable prices. Reasonable prices, fashionable theme base and tasty tangy flavors make these types of food joints more popular especially among youngster. The main purpose of this research is to study the impact of demonetization on the usage of E-wallet specifically in road side restaurants (RSR) in South Delhi and Faridabad city.

\section{REVIEW OF LITERATURE}

Numerous researches have been done since so many decades not only in India but across the world to investigate those factors that have a direct or indirect impact on an adoption of electronic mode of payment in service sector. Many earlier researches tried to find out about those responsible factors that play an important role in depicting customer's delight. Many investigators have identified the demand to establish and assess the criteria of service quality.

The growth of e-commerce in the global and regional markets creates a special interest in the measuring of e-service quality and also in the investigation of the dimensions of e-service (Mekoves et al., 2007).

According to Lee. et. all ( 2007), credit cards often are associated with more spending resulting in an increase in debt as well. Cash limits one's ability to spend to the amount of cash in hand, a debit card expands it to the balances available in the account and a credit card further relaxes it to include future earnings as well. (Morewedge, C. K., Holtzman, L., \& Epley, N. (2007).

Manjoor Amir, in his research study states that there are several benefits and advantages in adopting Ecommerce. It is helpful for doing Transactions at home. It also gives a universally accepted quality, security and reliability of product so that major part of share can be increased by particular website. According to Soman D. 2003, while cash limits one's ability to spend to the amount of cash in hand, a debit card expands it to the balances available in the account and a credit card further relaxes it to include future earnings as well.

Kotler (2009) Stated that core purpose of any fast food retailer must be related to providing value for money to its customers and employ advanced marketing \& communication channels to strengthen the overall marketing campaign. Goyal \& Singh (2007) have culminated that the young customers visit fast food channels for fun and change. Gupta (2003) found that customer perception, taste \& satisfaction develop more favorable consumer behavior towards particular brand than any other factor.

Abbasi, Chaudhry, Riaz and Zafar (2002) revealed that in today's market consumers are more fascinated to western culture and like to eat more outside. Fast food is the food item that can be prepared and served very quickly (Webster Dictionary, 1951).Changing consumer behavior and favorable demographics led India to witness a tremendous growth in fast food restaurant industry (Shanker, 2010).Structural changes in the demand for food in Asia have projected that Asian countries had been undergoing transformations in their economies supported by rapid urbanization and this trend would continue in the years to come. Huang and Howarth, (1996)

Antonia Trichopoulou, MD (2006) in his project entitled, "Consumers' attitude and behavior when eating out" stated that on one hand, eating out is related to special occasions and on other, it's part of people's daily routine. Kashyap, Kashyap \& Sarda (2013) in their study entitled, "A study of growth of fast food industry with reference to shift in consumer's buying habits in Nagpur city" stated that $50 \%$ of the people prefer to visit the fast food outlets once in a week. 
Malik, Kadyan \& Balyan(2013) in their article entitled "Food Habits of People In Haryana" made an attempt to examine the eating habits of people in Haryana which includes their liking for spicy/non-spicy food, number of meals taken in a day, preferred eating outlets and cooking equipments preferred. The people in Haryana have good eating habits and a large percentage of people prefer eating at home only. Prabhavathi, Krishan Kishore \& Ramesh (2014) in their study entitled, "Consumer Preference and Spending Pattern in Indian Fast food industry" highlighted that young consumers are looking for healthy food for their lifestyle and they expect foods which are homemade, nutritious and more of vegetables ingredients to suit for their healthy lifestyle.

\section{OBJECTIVES}

1. To find out the impact of demonetization on increased usage of E-wallet.

2. To study the customer buying behavior after demonetization.

3. To study the components affecting the frequency of customer's visits at restaurants.

4. To study the customer's perception towards roadside restaurants after demonetization.

\section{RESEARCH METHODOLOGY}

The data used for the present study is primary in nature. In order to collect primary data, self-administered questionnaire was used. The questionnaire was administered to about 150 people. The respondents included 86 males, 59 females and 06 transgender. The survey was carried out at few famous food joints of South Delhi \& Faridabad during months of November and December 2016. Convenience sampling approach was adopted in order to collect the primary data; however questionnaire was administered diligently to avoid biased errors. The respondents were the customers of few selected road- side restaurants (RSR) at South Delhi and Faridabad city.

\section{Demographic Profile of the Sample Respondents}

\begin{tabular}{|l|l|c|c|}
\hline Sl. No. & Demographic Variables & No. of respondents (n-150) & Percentage \\
\hline & Age & 50 & $33.33 \%$ \\
& $18-25$ & 27 & $18 \%$ \\
\hline & $26-30$ & 33 & $22 \%$ \\
\hline & $31-50$ & 40 & $26.66 \%$ \\
\hline & $50 \&$ \&above & 85 & $56.66 \%$ \\
& Gender & & $39.33 \%$ \\
\hline & Male & 59 & $4 \%$ \\
\hline & Female & 6 & $60 \%$ \\
\hline & Trans Gender & & $40 \%$ \\
\hline & Sarital Status & 90 & $30.66 \%$ \\
\hline & Married & 60 & $19.33 \%$ \\
\hline & Education & & $23.33 \%$ \\
\hline & Illiterate & 46 & $26.66 \%$ \\
\hline & Below 10 & 29 & \\
\hline & Graduate & 35 & $34 \%$ \\
\hline & Post Graduate & 40 & $21.33 \%$ \\
\hline & Income & & \\
\hline & Below 10,000 & 51 & 32 \\
\hline
\end{tabular}




\begin{tabular}{|c|l|c|c|}
\hline & $25000-50000$ & 27 & $18 \%$ \\
\hline & 50,000 and Above & 40 & $26.66 \%$ \\
\hline & $\begin{array}{l}\text { Occupation } \\
\text { Student }\end{array}$ & 51 & $34 \%$ \\
\hline & House Wife's & 19 & $12.66 \%$ \\
\hline & Salaried Class & 35 & $23.33 \%$ \\
\hline & Daily Wager & 45 & $30 \%$ \\
\hline
\end{tabular}

The above table shows the insights of the demographic profile of the respondents. The sample size chosen for the study was of 150 respondents which includes 85 males and 59 females. (33.33\%) of the sample belongs to the age group of 18-25 years and 18\% belongs to 26-30 years age group. Large numbers of respondents $(60 \%)$ were single and the rest $(40 \%)$ were married. It is evident from the table that $(34 \%)$ of respondents were students, $35 \%$ belonged to salaried class, $(12.66 \%)$ of respondents were housewife and rests were daily wagers. Majority of respondents (30.66\%) were illiterate and major part of the sample lied in the income group of below Rs. 10000.

\section{RESULT AND ANALYSIS}

The respondents were approached to collect information using Survey methodology making use of questionnaire as a tool. The discussions and summaries of the findings are given in distribution tables of frequency, percentages and figures.

The basic traits of the sample participants regarding age, gender, education, occupation, income and marital status of the sample respondents were analyzed and the results are presented below.

\subsection{GENDER}

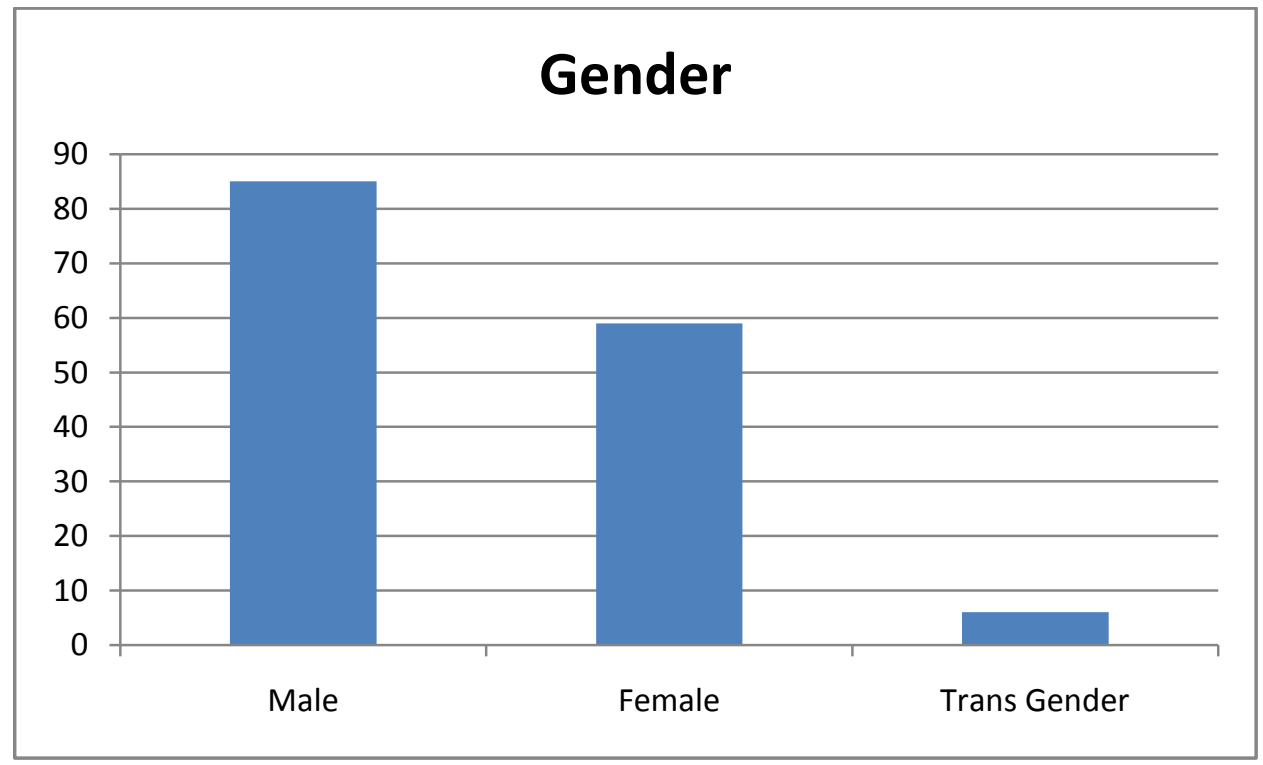

Figure -1

Inference: Gender plays an important role in any type of research depicting different pattern and lifestyle. They are different in terms of eating and spending habits. It could be observed from the figure 1 that male gender accounted for $56.66 \%$ and the remaining $39.33 \%$ were belonged to female gender and $4 \%$ belong to transgender category. From the graphs it is revealed that male do visit RSR more compare to females. 


\subsection{AGE}

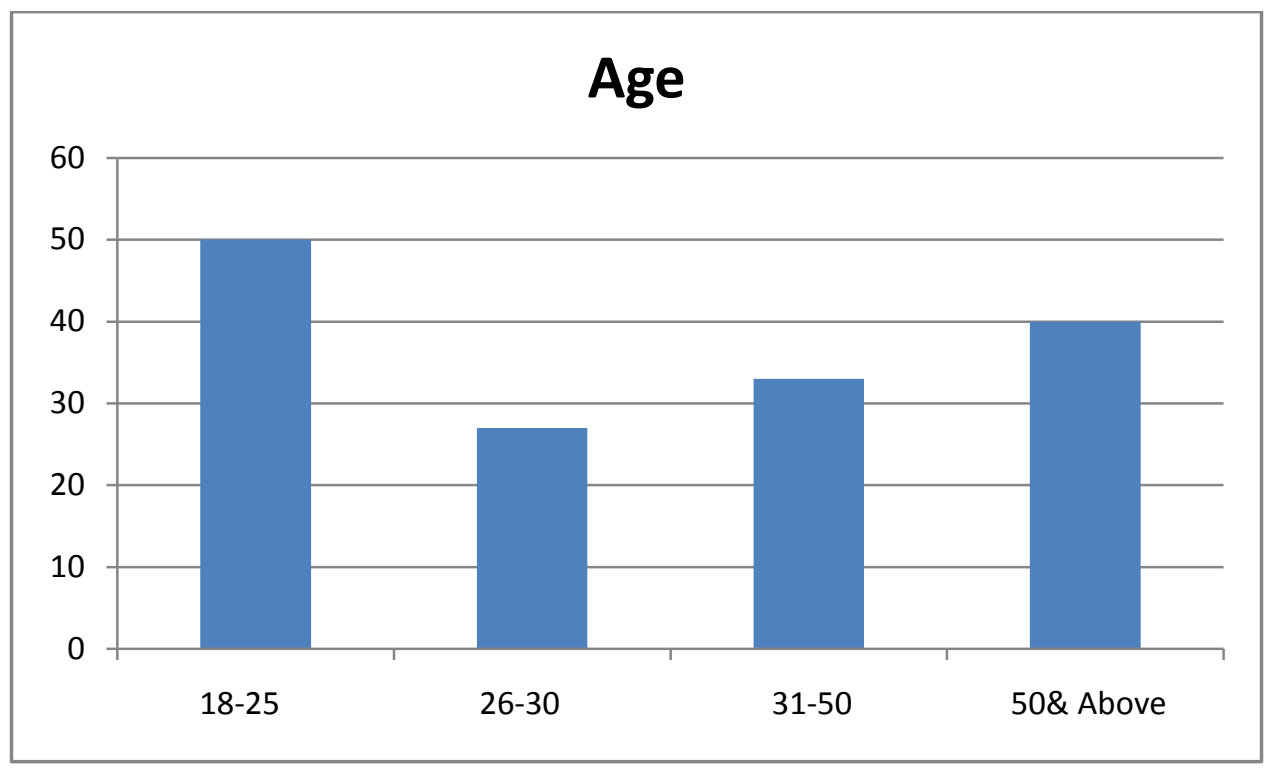

Figure-2

Inference: Age is an important demographic factor which determines individual person's lifestyle attitudes like thinking, decision making, risk bearing, etc. It could be inferred from the figure-2 that 50 per cent of the sample respondents were belonged to the age group of 10 to 25 years and 40 per cent of them were below to 50 years. It shows that majority of the respondents are in the age group of 18-25 years and are classified as young consumers.

\subsection{EDUCATIONAL QUALIFICATION}

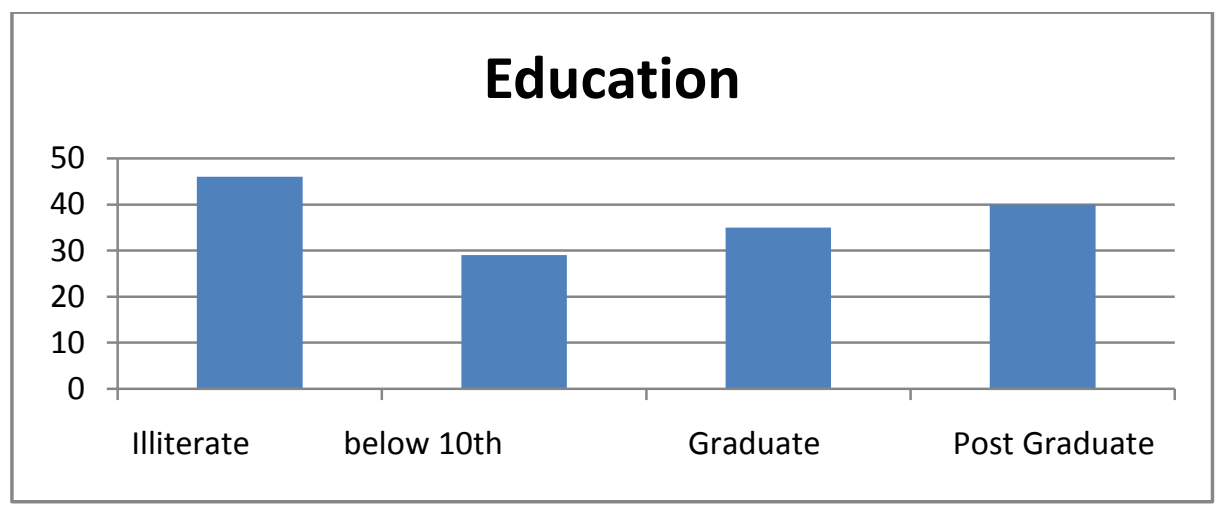

Figure- 3

Inference: Education is the main driver in influencing customer's attitude and behavior. Lifestyle and level of education are dependent on each other. It is clearly seen from the results (figure-3) that majority of respondents $(30.66 \%)$ are illiterate. (23.33\%) were graduates while $26.66 \%$ were post graduate. $19.33 \%$ respondents are on $10^{\text {th }}$ class passed. So, it can be inferred that majorly illiterate or less educated group forms the major consumer group in the current study. 


\subsection{MARITAL STATUS}

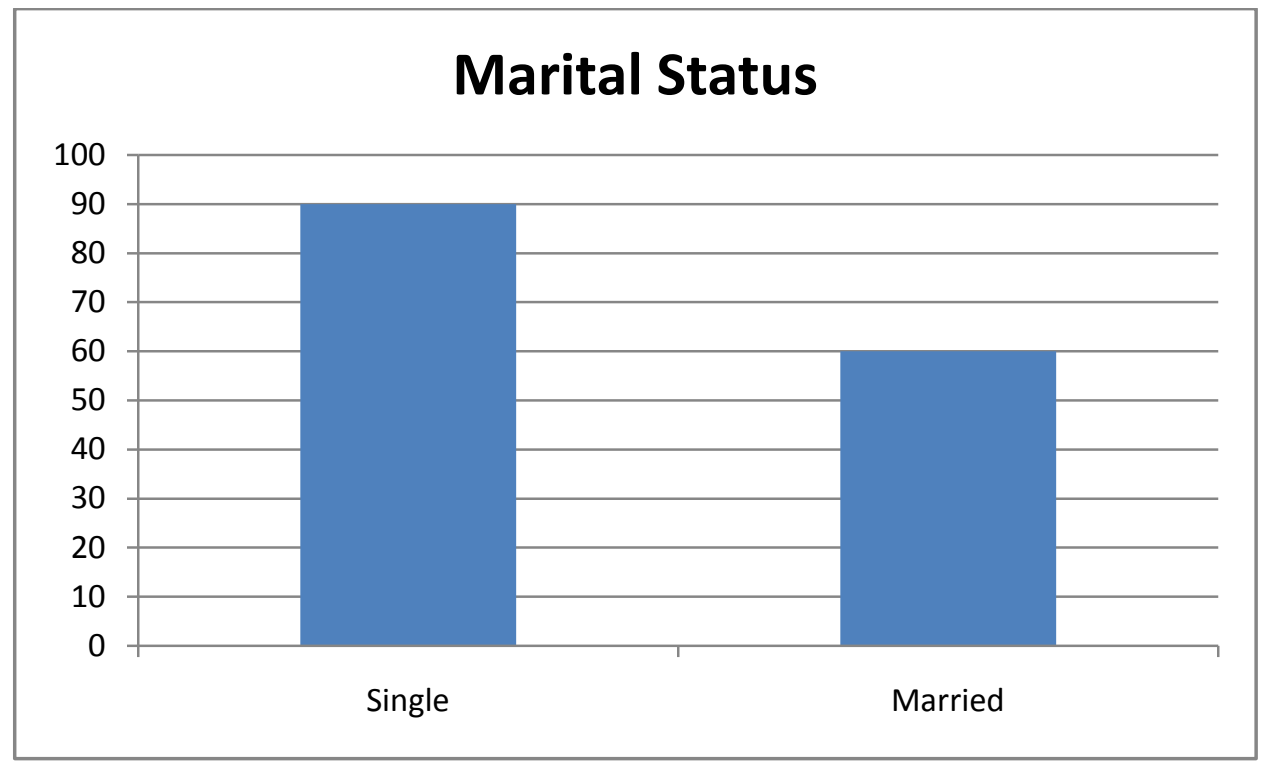

Figure-4

Inference: The marital status of sample respondents have major role in spending towards fast food. Hence, the details on marital status of sample respondents were analyzed and the results are presented in figure-4. It is observed from figure-4 that the majority of participants $(60 \%)$ were single 9unmarried group). They mostly belong to student category, in age group of 18-25. Remaining $40 \%$ participants are married; they belong to salaried class mostly in age group of 31-50. Hence, in the present study single, unmarried consumer groups formed the major category that prefers to visit RSR. These findings are in line with the results of Chae and Ryu (2010) where among the total respondents in Korea, 56.3 percent were single unmarried group and 43.7 per cent belonged to married group.

\subsection{OCCUPATION}

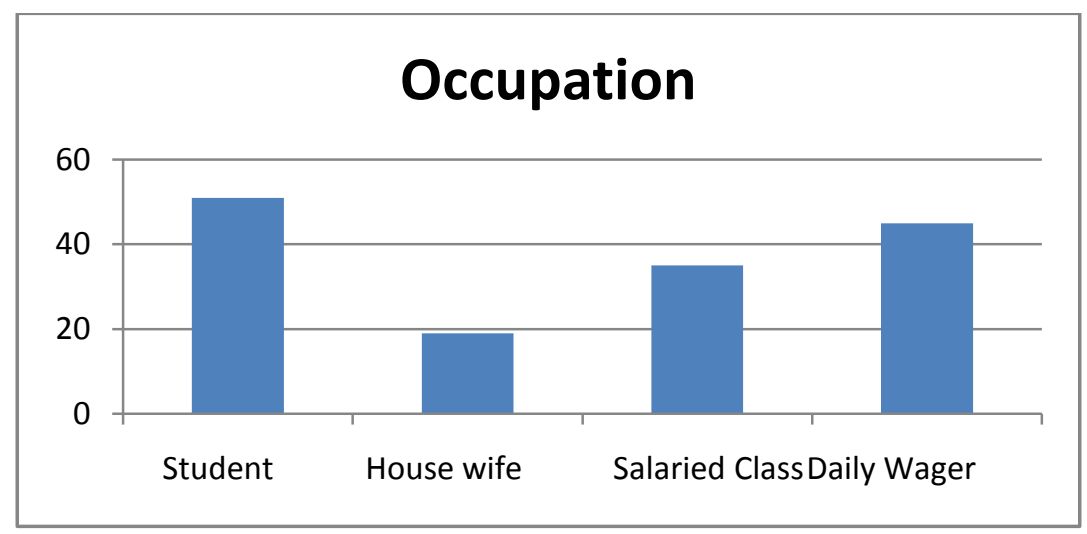

Figure-5

Inference: The occupational status of sample respondents was analyzed and the results are presented in the figure-5. The graph shows that majority of respondents are not working in students category. 30\% belong to daily wagers category. $23.33 \%$ are salaried class and rest $12.66 \%$ are housewives. It shows that 
majority of the sample respondents are not working group and other second largest category is of daily wager earning income on daily basis.

\subsection{INCOME}

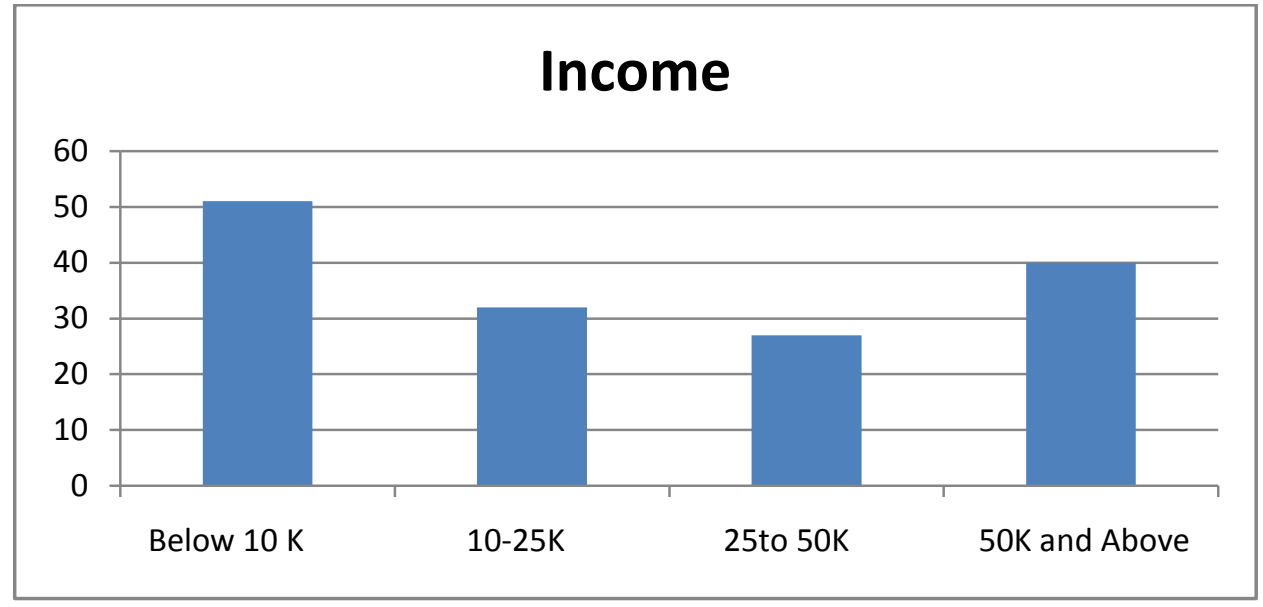

Figure-6

Inference: Income level of consumers has significant role in influencing the decision making process on their own. Increasing disposable income of consumers define their lifestyle, food habits and spending patterns. It could be observed from the figure- 6 that $34 \%$ of sample respondents had monthly income below Rs. 10000 followed by $26 \%$ per cent of the respondents earn more than Rs. 50000 and $21.33 \%$ of respondents having income range of Rs. 25000 to Rs.50000. It is also observed that only $18 \%$ per cent of them are earning a monthly income of Rs.18000. Hence, it is inferred that majority of the sample respondents earn monthly income below Rs.10000 and the average monthly income for the sample respondents was Rs. $21.33 \%$ per month.

\subsection{REASONS FOR GOING ROAD SIDE RESTAURANTS}

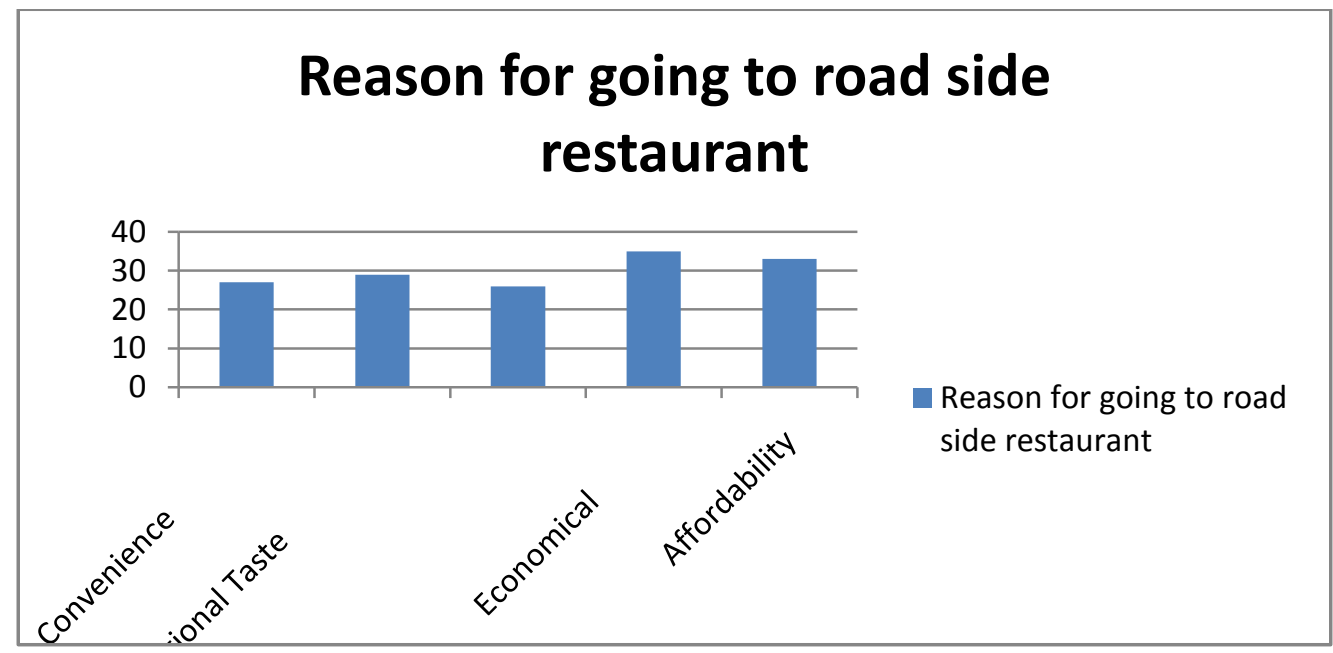

Figure -7 
Inference: Results of the study (figure-7).show that almost all respondents have a same opinion regarding roadside restaurants it is noticeable that they prefer them over other types of food joints due to their less expensive menu. $35 \%$ of the respondents feel that road side restaurants' offer best quality food at reasonable prices. $30 \%$ found them affordable. Regional taste is the third important factor of choosing these restaurants followed by convenience and peer influence. This is the indication of large widely acceptance of road side restaurants are affordable price menu.

\subsection{REASONS FOR GOING ROAD SIDE RESTAURANTS}

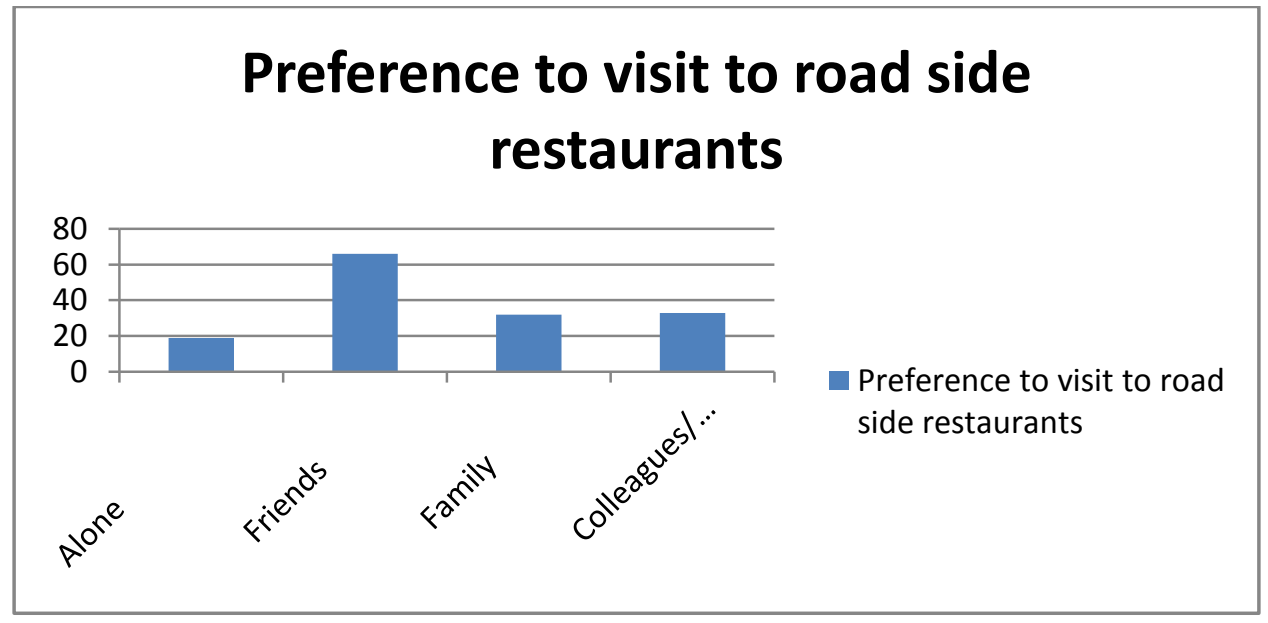

Figure-8

Inference: The figure no. 8 suggested that $68 \%$ of the respondents accepted that visiting restaurants with friends and colleagues is more enjoyable compare to going with family and alone. This low level of respondent's preference of visiting restaurants with families might lead to adoption of few creative ideas to make it more meaningful with family. Hence, It is inferred that people feel good and enjoy most by eating out at RSR with their friends and colleagues

\subsection{MONTHLY EXPENDITURE ON EATING OUTSIDE}

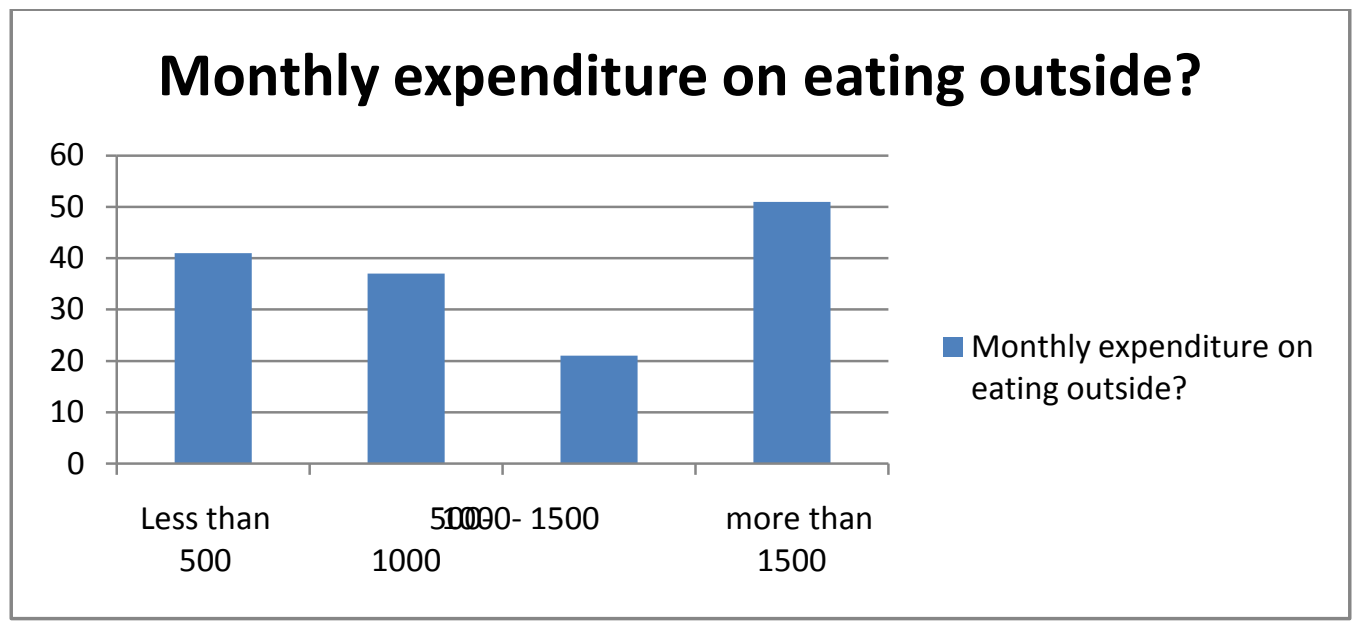

Figure-9 
Inference: It is clearly evident from the figure no. 9 that people mostly spend more than rs.1500 on eating out at road side restaurants. It shows their spending habits. From the exhibit 9, it can be learned that, participants spend more than 1500 in a month followed by less than 500 and between 1000-1500.

\subsection{PREFERENCE MODE OF PAYMENT}

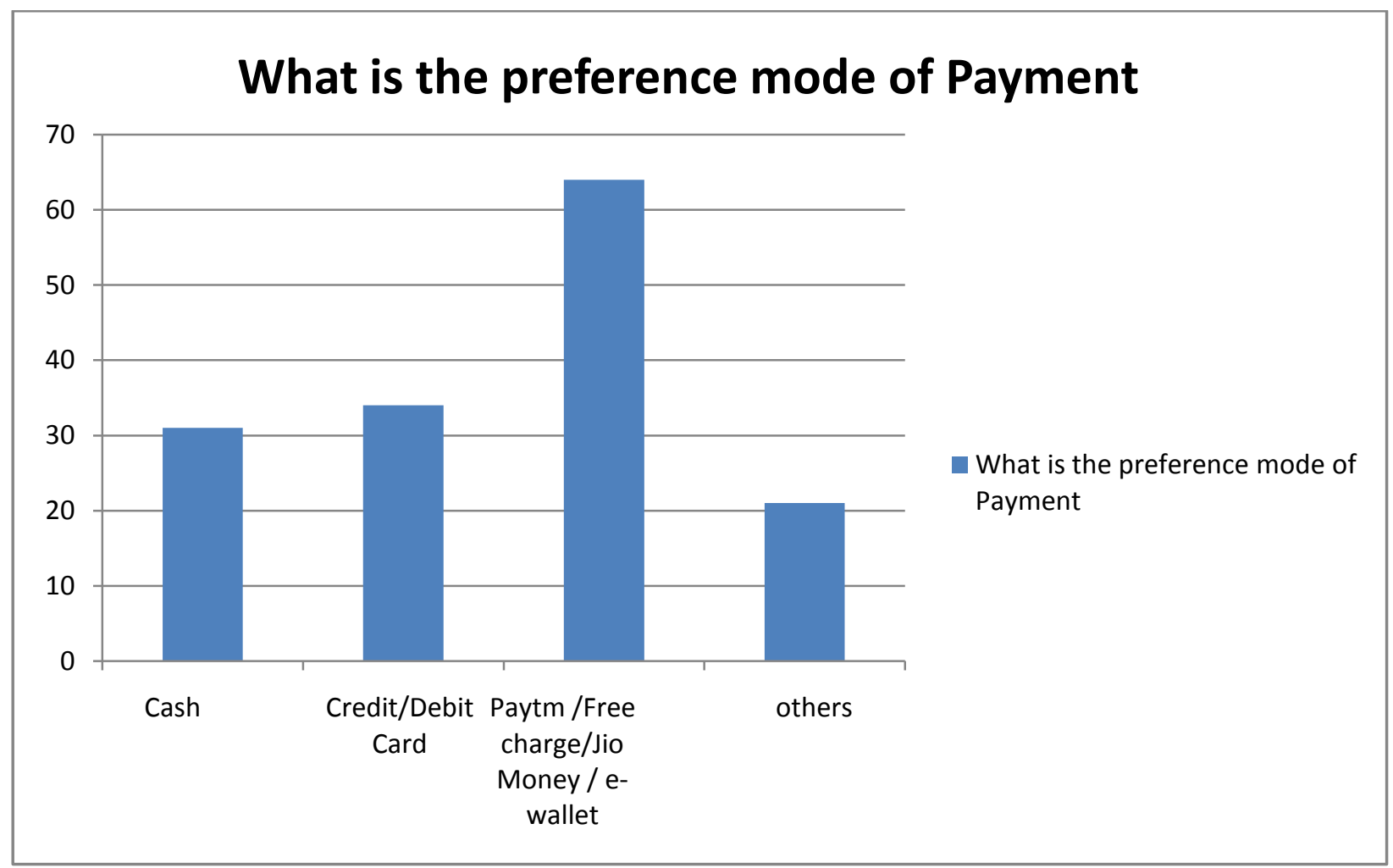

Figure-10

Inference: After demonetization, it is proved that people shifted from cash transaction to digital mode of payment. The candidates were asked during the survey that which electronic mode among all, they prefer most. It is clearly observed from the figure-10 that candidates are mostly using Paytm and free charge for making payment at road side restaurants. It could be observed from the figure - 10 that majority of the respondents $(65 \%)$ are using paytm, e-wallet and free charge. The candidates find these modes of digital payment more lucrative and benefitting like cash back discount. 


\subsection{DIGITAL MODE OF PAYMENT}

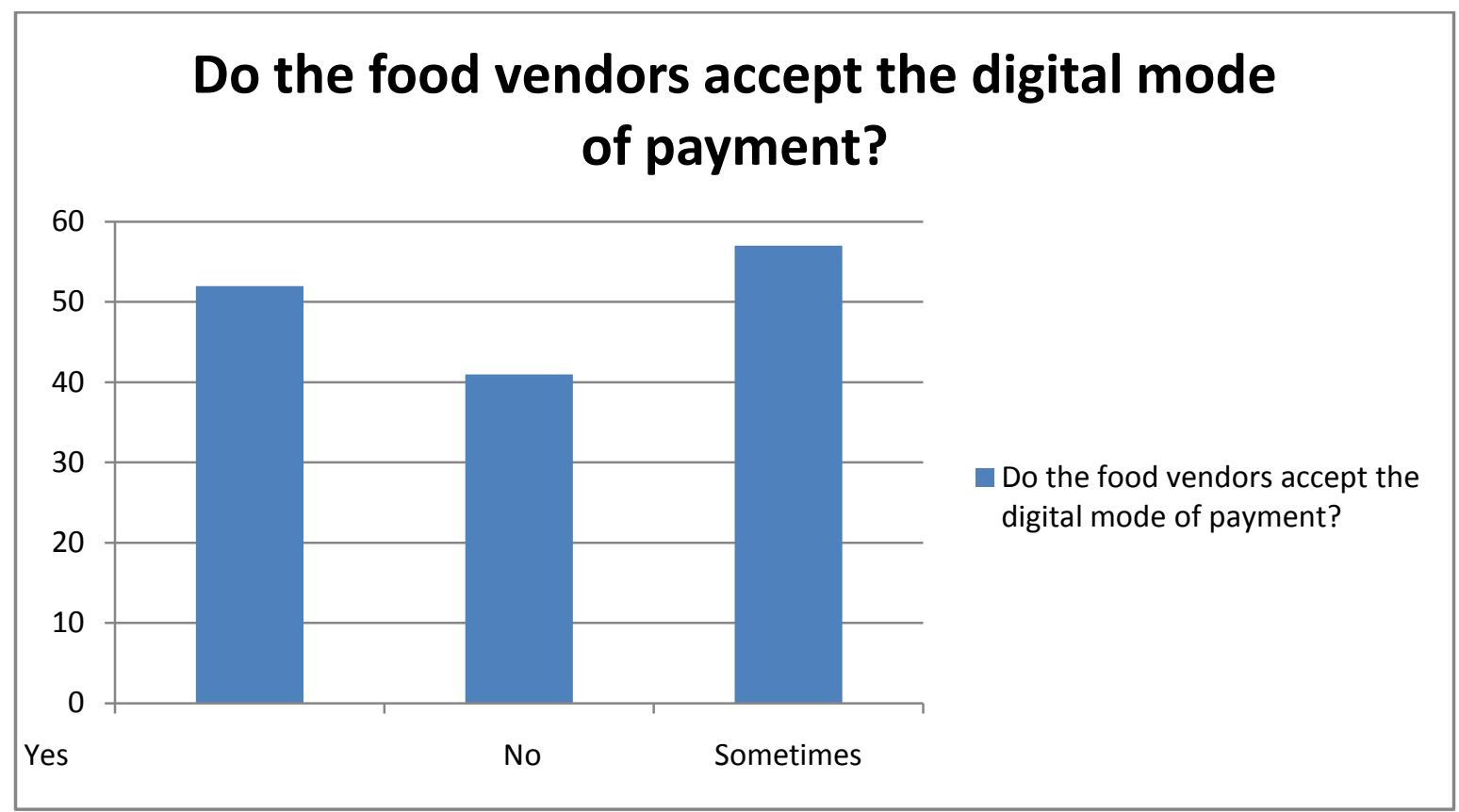

Figure-11

Inference: Demonization has a positive and negative impact on all fields of an economy. The previous researches reveal that businesses always suffer momentary whenever currency gets devaluate or fluctuates. The respondents were asked during the survey regarding mode of payment. All participants accepted that they do take digital payment at times but not all the times. They further accepted that after demonetization by force they have started accepting digital payment.

\subsection{ELECTRONIC MODE OF PAYMENT}

\section{What do you think is the reason why the vendors have started using the electronic mode of payment}

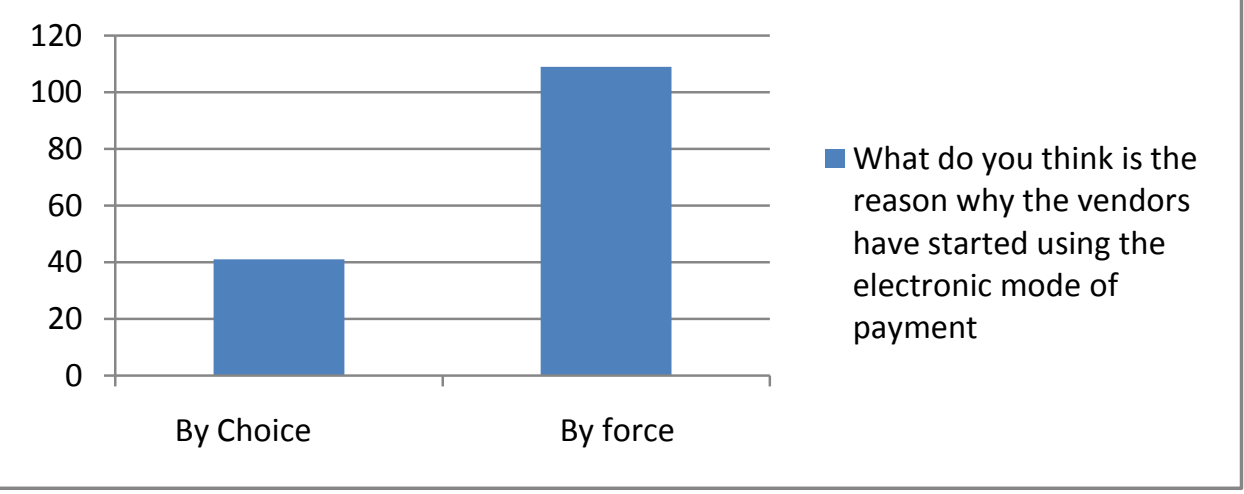

Figure-12 
Inference: Due to demonetization, every segment of society has shifted from cash transaction to digital transaction. Food and service industry are also not untouched by it. Facts reveal that vendor at small and medium both the levels have started accepting payment in virtual money. Through this study it was observed that after the ban of Rs. 500 \&Rs. 1000 notes, most of the road side restaurants shifted to digital mode of payment. It is noticeable from the figure 12 that majority of respondent feel that they are shifted to electronic mode of payment due to this financial crunch.

\section{CONCLUSON}

The Indian economy is experiencing a shock, because of a major decision taken by present government. The term demonetization leads a transition from cash to cashless economy. E-Commerce is going to play a major role in future business scenario. Today every common man has mobile connection and they prefer mobile phone for doing shopping and business transactions. Recent researches in India show the huge acceptance and success of digital mode of payments. In India fine dining has been accepting digital payment methods since long through credit and debit cards, but road side restaurants were only dependent on cash transaction.

After demonetization, RSR have been shifting into world of digitalization. Through the survey it was much cleared that small road side vendors had been shifting from cash payment to Mobile commerce. The entire research work revolves around figuring out the impact of demonetization on the consumer spending behavior and degree of usage of E-wallet. The study aimed to measure the effect on individuals who earn incomes in cash and spend it in cash. The research findings reveal that among the e-wallets majority of respondents are using paytm for transaction at RSRs. Vendors and respondents both are using mobile commerce and it is being used as the next generation mode of business. There are many substitutes for cash in the modern economy ranging from cheques, debit cards, pre-paid cards, credit cards and mobile wallets. When compared to cash, these instruments differ in a number of key characteristics. Changes in consumer behavior can have long-term consequences on the economy as well as on the budgets and lifestyles and priorities of agents in the economy.

\section{REFERENCES}

- Abbasi, R., Chaudhry, A., Riaz, A., Zafar, I. (2002), Consumer Behavior towards Fast Food. Pakistan Journal, 12(3-4).

- Antonia Trichopoulou, MD (2006), eating out: Determinants and recommendations for consumers and Europeans catering sector, Hector, Project, National and Kapodistrian University of Athens.

- Goyal, A. and Singh, N.P. (2007) Consumer Perception about Fast Food in India: An Exploratory Study. British Food Journal, 109, 182-195.

- Gupta, (2003) "A study of quick service restaurants with reference to consumer's perception and their behavior in Delhi NCR region, International Journal of Science, Technology \& management, Volume No 04, Special Issue No. 01, March 2015.

- Huang, J., \&Howarth, B. (1996). Structural changes in the demand for food in Asia. International Food Policy Research Institute.

- Lee, Jinkook, Fahzy Abdul-Rahman, and Hyungsoo Kim. "Debit card usage: an examination of its impact on household debt." Financial Services Review. 16.1 (2007): 73.

- Kashyap and Kashyap, International Journal of Application or innovation in Engineering and Management, Special issue for National Conference.

- Malik, Kadyan\&Balyan(2013), eating out Behavior of Individuals: A case study, International Journal in Management \& Social Science, 2014, Volume: 2, Issue: 10.

- Manzoor A. (2012). Broadband Internet development and economic growth: A comparative study 
of two Asian countries. IOSR Journal of Business and Management, 1, 1-14

- Mekoves, R, Bubas, G. \&Verck, N. 2007. "A method for improvement of objectivity of E- service quality". Journal of information and organizational sciences, Vol 31.

- MinalKashyap, \&KomalKashyap Dr. Anil Sarda, A Study of Growth of Fast Food Industry with Reference to Shift in Consumer's Buying Habits in Nagpur City, International Journal of Application or Innovation in Engineering \& Management. ISSN 2319 -4847.

- Morewedge, C. K., Holtzman, L., \& Epley, N. (2007). Unfixed resources: perceived costs, consumption, and the accessible account effect. Journal of Consumer Research, 34(4), 459-467).

- Prabhavathi, Krishna Kishore N. T. \& Kumar Ramesh M., (2014), Consumer Preference and Spending Pattern in Indian Fast Food Industry, International Journal of Scientific and Research Publications, Volume 4, Issue 2.

- Soman, D., (2003). The effect of payment transparency on consumption: Quasi-experiments from the field. Marketing Letters 14(3), 173-183. )

- Y Prabhavathi, N T Krishna Kishore, M. Ramesh Kumar, Problems and changing need of consumers in fast food industry: The Indian Perspective, international Journal of Scientific and Research Publications, Volume 4, Issue 2, February 2014 ISSN 2250 - 3153. 